\title{
Early ocular hypertension after cataract extraction
}

\author{
W. J. RICH*, N. D. RADTKE, AND B. E. COHAN \\ From the Department of Ophthalmology, The University of Michigan Medical Center, and Saint Joseph \\ Mercy Hospital, Ann Arbor, Michigan, U.S.A.
}

This study describes a dramatic rise in intraocular pressure which occurs within a few hours after cataract surgery without the use of $\alpha$-chymotrypsin. Early reports stated that intraocular pressures remained low after cataract surgery, but these statements were based on measurements made several days (Hilding, I955) or weeks after surgery (Miller, Keskey, and Becker, 1957). Applanation measurements made 12 hours after surgery were reported at or below the preoperative level (Galin, Baras, and Perry, r96r). Gormaz (1962, 1973) first reported ocular hypertension one day after cataract surgery and did not use $\alpha$-chymotrypsin. Giardini and Paliaga ( 1964 ) reported ocular hypertension 8 hours after cataract surgery with a technique which included the use of $\alpha$-chymotrypsin. The association of this enzyme with a postoperative rise in intraocular pressure was made by Kirsch (I964). Galin, Barasch, and Harris (1966) supported this relationship. However, in those eyes in which $\alpha$-chymotrypsin had not been used, Kirsch (r964) reported a 23 per cent. and Galin and others (1966) an 8 per cent. incidence of ocular hypertension, by their criteria. Rich ( I968) demonstrated a consistent rise in intraocular pressure one day after cataract surgery without the use of $\alpha$-chymotrypsin and with a technique designed to secure water-tight incision closure. He suggested that an early postoperative rise in intraocular pressure followed all cases of cataract surgery in which incision closure was water-tight.

\section{Methods}

Cataract surgery was performed on ten consecutive patients (Cases I to I0) whose eyes were otherwise normal. The age range was 54 to 86 yrs. Preoperative preparation of the patient included one drop of a steroid-antibiotic combination the night before and on the morning of surgery. Preoperative sedation was intramuscular diazepam Io $\mathrm{mg}$. one hour before surgery. No mydriatic or other medication, local or systemic, was used. The operations were performed under local anaesthesia with topical proparacaine 0.5 per cent. and facial nerve block and retrobulbar anaesthesia with lignocaine 2 per cent. with adrenaline $\mathrm{I}: \mathrm{I}$ ooo and hyaluronidase. The operations were performed by the same surgeon using a surgical microscope.

The anterior chamber was entered beneath a limbus-based conjunctival flap through a bevelled corneo-scleral incision; the outer two-thirds of this incision were vertical and the inner portion sharply angled anteriorly. Two corneo-scleral sutures of $25 \mu$ diameter Perlon were placed before the chamber was entered. The lens was removed by cryoextraction. $\alpha$-chymotrypsin was not used. The anterior chamber was then irrigated with $\mathrm{a} I$ in 200 solution of acetylcholine, the corneo-scleral sutures were tied, and a basal iridectomy was performed. The corneo-scleral incision was additionally

Address for reprints: Dr B. E. Cohan, Department of Ophthalmology, The University of Michigan Medical Center, Ann Arbor, Michigan 48105, U.S.A.

*W. J. Rich, F.R.C.S., West of England Eye Infirmary, Exeter, England 
supported by a continuous suture of Perlon, placed according to the locked technique of Worst and tied at either end (Ryan and Maumenee, 197I). This suture was placed deliberately to achieve water-tight closure: nine to eleven limbs crossed the incision and the end-limbs extended beyond the ends of the incision. No air was left in the anterior chamber. After closure of the conjunctival incision with a continuous suture of Perlon, a drop of pilocarpine 4 per cent. and a steroid-antibiotic drop were instilled.

Subsequently, a second series of ten consecutive cataract extractions (Cases I I to 20) were performed by another surgeon (WJR) in another centre.* In this group the age range was 6o to 87 yrs. The technique used in the primary series was followed as closely as possible in each detail.

Of the combined total of twenty cases, nine had a Worst intraocular acrylic lens (approximate volume ${ }_{15} \mu \mathrm{l}$.) inserted and held in place by a single iris suture.

Intraocular pressures were measured in both eyes with the Perkins hand-held applanation tonometer (Dunn and Brubaker, 1973) with the patient recumbent and the head supported by one pillow. This was done the evening before surgery, at the end of the surgical procedure while the patient was still on the operating table, hourly during the initial post-operative period, and then frequently during the remainder of the period of observation. (Final measurements were taken between $23 \frac{1}{2}$ and $26 \mathrm{hrs}$ after surgery in the first series and between 24 and $30 \mathrm{hrs}$ in the second series.) The mean number of measurements per patient was fifteen in the primary series and nine in the second. A mean of three readings was taken for each measurement. At each observation assessment was made of the degree of recovery from anaesthesia by noting orbicularis oculi and extraocular muscle function. Observation of the cornea and anterior chamber was made at frequent intervals with the Haag-Streit 9oo slit lamp. Particular note was made of symptoms; patients were instructed to ask the nursing staff for an analgesic capsule (propoxyphene $65 \mathrm{mg}$. with acetylsalicylic acid $227 \mathrm{mg}$.) when they felt the need.

\section{Results}

Table I summarizes intraocular pressure and time data for each of the twenty patients. Preoperative intraocular pressures were within the normal range with a mean of $16.4 \mathrm{~mm}$. $\mathrm{Hg}$, and there was no significant difference between the eye for surgery and the fellow eye. Intraocular pressures at the end of surgery, on the operating table, were unmeasurably low. In every case, the intraocular pressure began to rise before the third postoperative hour. The mean time taken for intraocular pressures to regain their preoperative levels was 3.2 hrs (range $I^{\cdot} 25^{-I}$ ). In every case, the pressure rise continued beyond this level to reach a maximum mean value of $39.3 \mathrm{~mm}$. $\mathrm{Hg}$ (range 26-50) at a mean time of $6.8 \mathrm{hrs}$ (range 3.25-20) after surgery. The mean rate of initial intraocular pressure rise was $7.9 \mathrm{~mm}$. $\mathrm{Hg}$ per hour (range $2 \cdot 5^{-20}$ ). After the period of rapid increase, the intraocular pressure in each case showed persistent elevation which in most cases extended beyond the observation period. The mean of measurements at the end of the observation period was $23 . \mathrm{Imm} . \mathrm{Hg}$ (range 10-50). The Figure (overleaf) shows the intraocular pressure curves during the observation period for each patient. Intraocular pressures in the fellow eyes remained within normal limits.

Orbicularis oculi and extraocular muscle movements were estimated to be normal at the time of the first post-operative measurement I hour after surgery in every patient except one in whom this period extended to 2 hours. Table II (overleaf) gives the data relating pain to pressure and time for each patient. Pain in and around the eye was noted by eighteen of twenty patients; the mean time of onset was $3.2 \mathrm{hrs}$ (range 2-5) after surgery and the mean time pain ended was $5.5 \mathrm{hrs}$ (range $4-7$ ) after surgery. Mean intraocular pressure at 
Table I Intraocular pressure $(I O P)$ response after cataract surgery in twenty patients

\begin{tabular}{|c|c|c|c|c|c|c|c|}
\hline \multirow{3}{*}{$\begin{array}{l}\text { Patient } \\
\text { no. }\end{array}$} & \multicolumn{4}{|c|}{ Intraocular pressure $(\mathrm{mm} . \mathrm{Hg})$} & \multirow{3}{*}{$\begin{array}{l}\text { Initial } \\
\text { rate of } \\
\text { IOP rise } \\
(\mathrm{mm} . \mathrm{Hg} / \\
\mathrm{hr})\end{array}$} & \multicolumn{2}{|c|}{ Time postoperative (hrs) } \\
\hline & \multicolumn{2}{|c|}{ Preoperative } & \multicolumn{2}{|c|}{ Postoperative } & & Preoperative & Maximum \\
\hline & $\begin{array}{l}\text { Fellow } \\
\text { eye }\end{array}$ & $\begin{array}{l}\text { Study } \\
\text { eye }\end{array}$ & Maximum & I day & & $\begin{array}{l}I O P \\
\text { regained }\end{array}$ & $\begin{array}{l}I O P \\
\text { reached }\end{array}$ \\
\hline I & I6 & 18 & $5^{0}$ & $3^{8}$ & 7 & $I \cdot 75$ & $4 \cdot 5$ \\
\hline 2 & I 3 & I3 & 34 & I9 & 8 & $2 \cdot 0$ & $4^{\cdot 0}$ \\
\hline 3 & I 4 & I 3 & 28 & 22 & 12 & $2 \cdot 75$ & $4^{\cdot 0}$ \\
\hline 4 & 22 & 20 & $4^{2}$ & 27 & 5 & $15^{\circ} \mathrm{O}$ & $20 \cdot 0$ \\
\hline 5 & I 2 & I 8 & 35 & IO & 5 & $4^{\cdot 0}$ & $16 \cdot 0$ \\
\hline 6 & 20 & I 8 & 34 & I9 & 8 & $4^{\circ} \cdot 0$ & $7 \cdot 0$ \\
\hline 7 & 15 & 20 & $4^{8}$ & 30 & I 2 & $2 \cdot 75$ & $8 \cdot 0$ \\
\hline 8 & I 8 & I 5 & $5^{0}$ & $5^{0}$ & 7 & $3 \cdot 5$ & $7 \cdot 0$ \\
\hline 9 & I 5 & I 6 & 40 & 30 & I I & $1 \cdot 5$ & $6 \cdot 5$ \\
\hline 10 & I 4 & I 7 & 27 & I3 & 9 & $2 \cdot 5$ & $6 \cdot 5$ \\
\hline I I & $2 I$ & I 8 & 45 & 24 & Io & $2 \cdot 5$ & $6 \cdot 25$ \\
\hline 12 & I6 & 18 & 50 & I 8 & 8 & $2 \cdot 5$ & $5 \cdot 75$ \\
\hline 13 & I 6 & I 4 & $4^{0}$ & 14 & 12 & $2 \cdot 5$ & 5.5 \\
\hline 14 & I I & I 6 & 26 & I 6 & 4 & $3 \cdot 0$ & $4 \cdot 5$ \\
\hline I 5 & I 3 & I 6 & 43 & 20 & 5 & $2 \cdot 0$ & $4 \cdot 75$ \\
\hline I 6 & I 6 & I 6 & 43 & 30 & 6 & $3 \cdot 5$ & $7 \cdot 75$ \\
\hline I 7 & IO & I 6 & 40 & 20 & 3 & $I \cdot 25$ & $6 \cdot 9$ \\
\hline I 8 & I 4 & I 6 & 30 & I 8 & 4 & $2 \cdot 0$ & $4 \cdot 5$ \\
\hline 19 & I9 & I 8 & 30 & I 8 & 4 & $3 \cdot 25$ & $5 \cdot 0$ \\
\hline 20 & I3 & I I & $5^{0}$ & 25 & 20 & $\mathbf{I} \cdot 5$ & $3 \cdot 25$ \\
\hline Mean & $15 \cdot 4$ & I $6 \cdot 4$ & $39 \cdot 3$ & $23 \cdot 1$ & $8 \cdot 0$ & $3 \cdot 2$ & $6 \cdot 8$ \\
\hline S.D. & $\pm 3 \cdot 3$ & $\pm 2 \cdot 3$ & $\pm 8 \cdot 3$ & \pm 9.3 & $\pm 4 \cdot 1$ & $\pm 2 \cdot 9$ & $\pm 4 \cdot I$ \\
\hline
\end{tabular}

the onset of pain was $2 \mathrm{I} \cdot 6 \mathrm{~mm}$. $\mathrm{Hg}$ (range 3-39) and mean intraocular pressure at the end of pain was $32.5 \mathrm{~mm}$. $\mathrm{Hg}$ (range I I-50).

The twenty cases in this study were divided into groups for statistical comparison: the first series of ten was compared with the second series of ten, and the nine cases in which an intraocular acrylic lens was used were compared with the eleven cases in which the lens was not used. All the differences of the means except one are not significant as determined by the t-test at the 0.05 per cent. level. Only the intraocular pressure at the onset of pain was significantly different between the first and second series.

\section{Discussion}

The rapid rise in intraocular pressure which we have observed after cataract extraction without $\alpha$-chymotrypsin may be due to volume changes in the aqueous, uveal, or vitreous compartments or some combination of these. However, we will limit our comments to possible mechanisms with regard to aqueous dynamics. During surgery, no attempt was made to replace aqueous loss, and at the end of surgery the intraocular pressures were too low to measure; this finding indicates an aqueous deficit of unknown volume. At that time, however, the anterior chamber had re-formed spontaneously in every case. This observation 

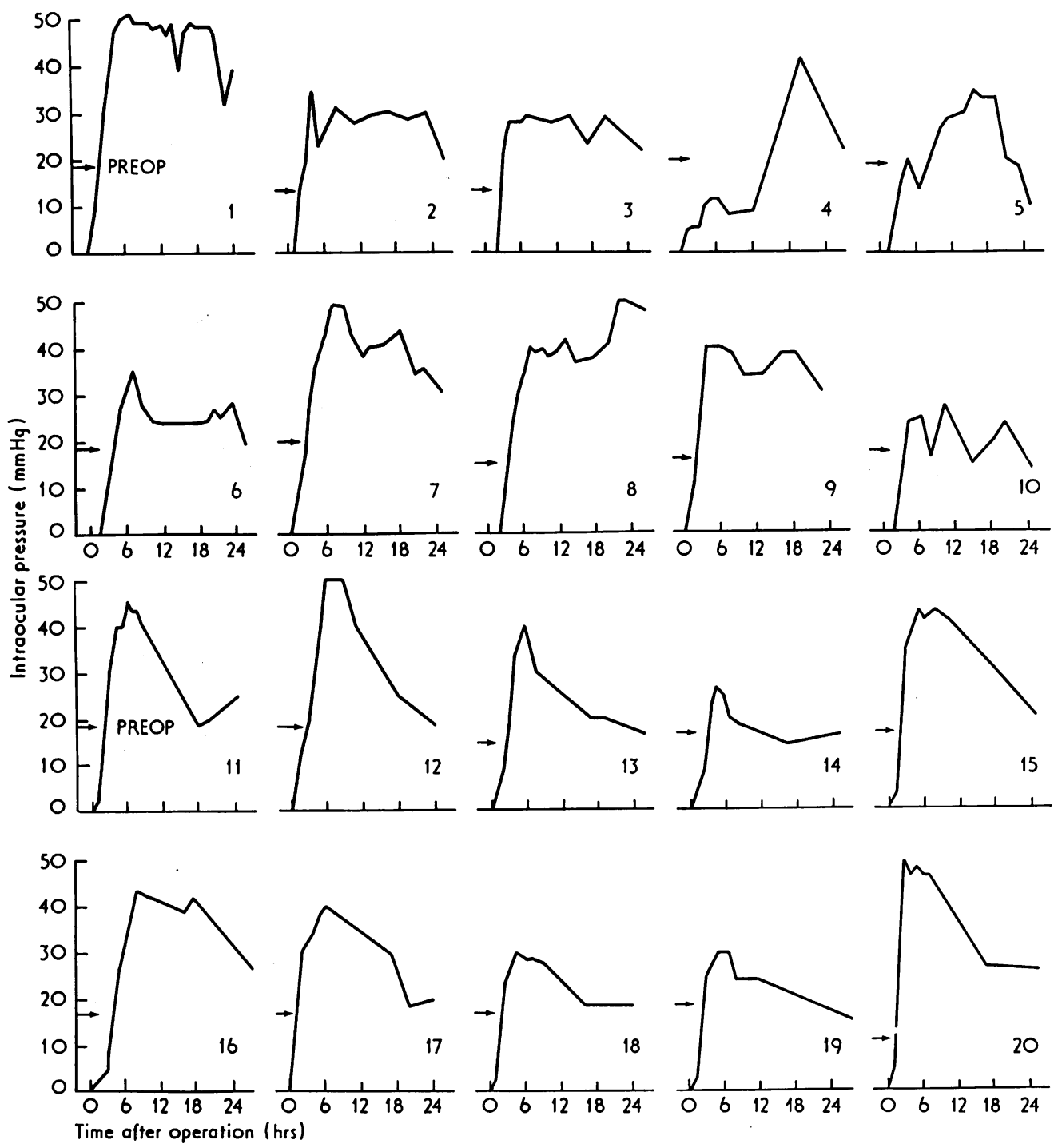

F IGURE Intraocular pressure curves during observation period for twenty patients

suggests that a phase of rapid aqueous formation occurs during the very early postoperative period. This is consistent with the study of the rate of restoration of aqueous volume following paracentesis of the anterior chamber in normal human eyes made by Kronfeld (1953).

The similarity of the ascending limbs of the pressure curves is apparent in the Figure; when values are calculated, using measurements above Io $\mathrm{mm}$. $\mathrm{Hg}$, the mean rate of rise in intraocular pressure is $7 \cdot 9$ (S.D. $\pm 4 \cdot \mathrm{I}$ ) $\mathrm{mm}$. Hg per hour. That the rate of rise in intraocular pressure from the baseline to the maximum level was uniform makes it seem unlikely that new factors become involved during this period. The pressure-volume data of Langham and Eisenlohr ( 1963 ) are applicable to that segment of the rise in intraocular pressure from Io $\mathrm{mm}$. $\mathrm{Hg}$ upwards and show that an increase in intraocular volume of approximately $5^{\circ} \mu \mathrm{l}$. must occur to produce a rise from $10 \mathrm{~mm}$. $\mathrm{Hg}$ to the mean maximum level $\left(39^{\circ} 3 \mathrm{~mm}\right.$. $\mathrm{Hg}$ ). If aqueous dynamics are involved in the postoperative pressure rise, a volume of 
Table II Data relating pain to time and intraocular pressure $(I O P)$ for twenty patients

\begin{tabular}{|c|c|c|c|c|}
\hline \multirow[b]{2}{*}{$\begin{array}{l}\text { Patient } \\
\text { no. }\end{array}$} & \multicolumn{2}{|c|}{ Onset of pain } & \multicolumn{2}{|c|}{ End of pain } \\
\hline & $\begin{array}{l}\text { Time } \\
(h r s)\end{array}$ & $\begin{array}{l}I O P \\
(\mathrm{~mm} . \mathrm{Hg})\end{array}$ & $\begin{array}{l}\text { Time } \\
\text { (hrs) }\end{array}$ & $\begin{array}{c}I O P \\
(m m . H g)\end{array}$ \\
\hline I & $2 \cdot 5$ & 30 & $6 \cdot 0$ & $5^{0}$ \\
\hline 2 & $2 \cdot 0$ & 14 & $4 \cdot 0$ & 36 \\
\hline 3 & $3 \cdot 0$ & $2 \mathrm{I}$ & $5^{\cdot 0}$ & 28 \\
\hline 4 & $4 \cdot 0$ & 10 & $6 \cdot 0$ & I I \\
\hline 5 & 3.5 & I 5 & $5 \cdot 0$ & 16 \\
\hline 6 & $3 \cdot 0$ & 9 & $6 \cdot 8$ & 34 \\
\hline 7 & $2 \cdot 5$ & 17 & $6 \cdot 5$ & 47 \\
\hline 8 & $5 \cdot 0$ & 30 & $6 \cdot 0$ & 34 \\
\hline 9 & $3 \cdot 3$ & 29 & $6 \cdot 0$ & 40 \\
\hline Io & $2 \cdot 2$ & 3 & 4.5 & 24 \\
\hline \multicolumn{5}{|l|}{ I I } \\
\hline 12 & $3 \cdot 0$ & $2 \mathrm{I}$ & $4^{\circ} \mathrm{O}$ & $3^{I}$ \\
\hline I3 & $4 \cdot 0$ & 32 & $5 \cdot 5$ & 40 \\
\hline 14 & $3 \cdot 5$ & 22 & $5 \cdot 0$ & 26 \\
\hline 15 & $4 \cdot 0$ & 39 & $5 \cdot 0$ & 46 \\
\hline I6 & $4^{\circ} 0$ & 20 & $6 \cdot 0$ & 33 \\
\hline 17 & $2 \cdot 25$ & 30 & $4 \cdot 25$ & 35 \\
\hline I 8 & $2 \cdot 5$ & 22 & $6 \cdot 0$ & 28 \\
\hline 19 & $2 \cdot 75$ & 25 & $7 \cdot 0$ & 30 \\
\hline 20 & & & & \\
\hline Mean & $3 \cdot 2$ & $21 \cdot 6$ & $5 \cdot 5$ & $32 \cdot 5$ \\
\hline S.D. & \pm 0.8 & $\pm 9 \cdot 2$ & \pm 0.9 & $\pm 9 \cdot 8$ \\
\hline
\end{tabular}

aqueous in excess of $5^{\circ} \mu \mathrm{l}$. must have been formed to account for the rise in pressure from unmeasurably low to the maximum. Any additional aqueous formation (normal rate approximately $2 \mu \mathrm{l}$. per minute) must be accounted for by outflow. Bulk flow of aqueous during the early postoperative period was suggested by an observation made in four cases: in each an hyphaema estimated to be one-fifth of the total anterior chamber volume cleared not only rapidly but during the period of rising intraocular pressure.

The persistent elevation of intraocular pressure after the initial rapid rise suggests the intervention of a new factor. Aqueous leak through the incision in the presence of relatively stable intraocular pressure assumes equal volumes of formation and leakage; it would seem likely that such a leak would produce irregular fluctuation of intraocular pressure. Another possibility is that outflow pathways become functional at this level of intraocular pressure and then permit a new steady state to be established. It is also possible that the maximum intraocular pressure coincides with the critical closing pressure of the capillaries of the ciliary body, thus reducing aqueous formation and resulting in a new steady state at this pressure level. Tonography will probably not resolve these factors. Kirsch (1965) claimed that the near-flat tonograms he recorded at the elevated intraocular pressures which he associated with the use of $\alpha$-chymotrypsin were strong evidence in favour of impairment of outflow. However, if bulk flow of aqueous is occurring and the outflow mechanism is already 
functioning at its limit at this pressure level, increasing pressure still more during tonography would not elicit additional outflow and would result in a flat tonogram. Regarding the possibility of outflow impairment as a factor, Rich (1969) demonstrated a significant rise in intraocular pressure after cataract surgery which had been performed through a corneal section designed to avoid direct surgical trauma to the outflow system. It is possible that some indirect effect on the outflow system or even debris in the trabecular meshwork are factors in the phenomenon we have described. In studies of $\alpha$-chymotrypsin effects, indirect damage to the outflow system in two recently operated human eyes has been suggested (Fanta, 1963), and zonular debris in the trabecular meshwork has been demonstrated experimentally in monkey eyes (Anderson, 1971) and in eye-bank eyes (Worthen, 1972).

Pain showed remarkably consistent characteristics in this study. Eighteen of twenty patients volunteered the presence of pain to the medical staff and fifteen requested the analgesic capsule from the nursing staff; yet none required a more potent analgesic. While recovery from anaesthesia, based on return of motor function, occurred about $2 \frac{1}{2}$ hours after the local injections, the onset of pain occurred $I \frac{1}{2}$ hours later. Since the duration of sensory loss is about one-third longer than motor loss after lignocaine block of the human ulnar nerve (Albért and Löfström, I96r), the onset of pain in our cases might be coincident with recovery from anaesthesia. We are, therefore, uncertain about attaching significance to the close association between the onset of pain and the return of intraocular pressure to the preoperative level. What is clearly significant is that pain ended by the time intraocular pressure had reached its maximum level. Thus, although intraocular pressure persisted at a high level, patients did not complain of pain or request analgesic capsules. Therefore, if the pain which follows cataract surgery is related to increased intraocular pressure, it is due to the rapid rise, not to the level, of intraocular pressure. In Case 4, two distinct episodes of pain occurred, the firsc 4 hours after surgery at the onset of the rise in pressure and the second 17 hours postoperatively at the time of a sharp second increase in intraocular pressure. Practically it is thus possible to anticipate the onset and duration of pain after cataract extraction and the time analgesics may benefit the patient.

Another, perhaps similar, observation was made with regard to the cornea. Accurate postoperative measurements with the Haag-Streit pachometer were difficult because of the presence of folds in Descemet's membrane. Nevertheless, during the period of increasing intraocular pressure, the central corneal thickness increased approximately $0.15 \mathrm{~mm}$. over the preoperative measurement and this was followed by slit-lamp evidence of diffuse haze throughout the entire cornea. Although both surgical trauma and increasing intraocular pressure could be factors which produced the thickening and haze, the changes noted involved the entire cornea uniformly, and not only the upper half. There was unequivocal clearing of the corneal haze during the phase of persistent ocular hypertension. These observations suggest that the corneal endothelium may adapt rapidly at a high level of intraocular pressure. Regarding long-term effects of these corneal changes, Miller and Dohlman (1970) reported a small, but significant, increase in corneal thickness 6 months after cataract surgery and attributed this to surgical trauma. If this phenomenon of ocular hypertension can be shown to contribute to permanent increase in corneal thickness, therapy to counteract it may be indicated to protect the cornea of the aphakic eye.

While our studies of ocular hypertension have been limited to the early postoperative period, no obvious lasting effects of this phenomenon have been noted in a large number of cases in which it was present on the day after surgery. We feel that this phenomenon becomes manifest to the extent that incision closure is water-tight and that the mechanisms for its production are probably present in every cataract extraction whether or not $\alpha$-chymo- 
trypsin is used. With less than water-tight incision closure, the increasing intraocular pressure may be contained for a time and a sudden leak may then precipitate iris prolapse or shallow anterior chamber. Water-tight incision closure may prevent these postoperative complications. Treatment of the transient ocular hypertension, if necessary, should probably be directed at the pressure itself and should not be attained by intentionally permitting leakage through the incision.

\section{Summary}

Ocular hypertension within hours after surgery was demonstrated in every one of twenty consecutive uncomplicated cataract extractions without $\alpha$-chymotrypsin. Intraocular pressures rose acutely to a maximum level $2 \cdot 4$ times the preoperative level (range 26-50 $\mathrm{mm} . \mathrm{Hg}$ ) at a mean time of $6.8 \mathrm{hrs}$ after surgery. Pain and corneal oedema were observed at the time of the rise in intraocular pressure, but did not continue despite persistent high intraocular pressures. Although the operations were performed in two series by surgeons in separate centres and in nine cases an intraocular acrylic lens was sutured to the iris, neither of these two factors produced significant differences in the results. The possible mechanisms and therapeutic consequences of the postoperative hypertension phenomenon are discussed. It is emphasized that this phenomenon is made manifest by water-tight incision closure and that less secure incision closure may permit this rise in pressure to be a factor in common postoperative complications.

The authors wish to thank Miss M. A. Angel and Miss M. J. Oberle for their assistance.

This study was supported in part by Public Health Service Research Grant EY o1076 from the National Eye Institute, Bethesda, Maryland, U.S.A., and by a travel fellowship from The Royal Society of Medicine, London, England.

\section{References}

ALBÉRT, J., and LÖFSTRÖM, в. (196I) Acta anaesth. scand., 5, 99

Anderson, D. R. (1971) Amer. 7. Ophthal., 71, 470

DUNN, J. s. , and BRUBAKer, R.F. (r973) Arch. Ophthal. (Chicago), 89, I49

fanta, H. (1963) Klin. Mbl. Augenheilk., 142, 10 I I

GAlin, M. A., BARAS, I., and PERry, R. (I96I) Arch. Ophthal. (Chicago), 66, 8o

- Barasch, K. R., and harris, L. s. (1966) Amer. F. Ophthal., 6r, 690

Giardini, A., and Paliaga, G. P. (1964) Brit. F. Ophthal., 48, i 33

gormaz, A. (1962) Amer. F. Ophthal., 53, 832

(1973) Personal communication

HILding, A. c. (1955) A.M.A. Arch. Ophthal. 53, 686

KIRSCH, R. E. (1964) Ibid., 72, 6 I 2

- (1965) Trans. Amer. Acad. Ophthal. Otolaryng., 69, г г I

Kronfeld, P. c. (1953) Amer. F. Ophthal., 36, I271

LANGHAM, M. E., and eisenlohr, J. E. (1963) Invest. Ophthal., 2, 72

Miller, D., and Dohlman, C. H. (1970) Trans. Amer. Acad. Ophthal. Otolaryng., 74, 369

MILlER, J. E., KESKEy, G. R., and BECKer, B. (1957) A.M.A. Arch. Ophthal., 58, 401

RICH, w. J. (I968) Trans. ophthal. Soc. U.K., 88, 437

- (I969) Ibid., 89, 639

RYan, s. J., and maumenee, A. E. (1971) Arch. Ophthal. (Chicago), 85, 302

worthen, D. M. (1972) Amer. 7. Ophthal., 73, 637 